\title{
Stable and radiogenic strontium isotopes in seawater over the Late Quaternary
}

\author{
M.M. Wood*, M. TAtzel, S. Pit And A. PAYTAN
}

University of California-Santa Cruz, Santa Cruz, CA 95064

USA (*correspondence: mamwood@ucsc.edu)

The isotopic composition of strontium $(\mathrm{Sr})$ in seawater is governed by the input fluxes from continental weathering and hydrothermalism and by the balance between marine carbonate deposition and dissolution. Radiogenic $\mathrm{Sr}$ isotopic ratios $\left({ }^{87} \mathrm{Sr} /{ }^{86} \mathrm{Sr}\right)$ have traditionally been used to study changes in weathering rates and hydrothermal activity. Stable $\mathrm{Sr}$ isotopic ratios $\left(\delta^{88 / 86} \mathrm{Sr}\right)$, which reflect both the inputs and outputs of $\mathrm{Sr}$ to/from the ocean, may be combined with ${ }^{87} \mathrm{Sr} /{ }^{86} \mathrm{Sr}$ measurements to more fully characterize the ocean Sr budget.

We present a reconstruction of seawater ${ }^{87} \mathrm{Sr} /{ }^{86} \mathrm{Sr}$ and $\delta^{88 / 86} \mathrm{Sr}$ over the past 0.5 million years, as recorded by marine barite. Insight from this record will improve our understanding of the driver(s) of the observed isotopic disequilibrum of $\mathrm{Sr}$ in modern day seawater [1] by constraining changes in continental weathering and carbonate deposition/dissolution over glacial periods. Preliminary results have demonstrated a measureable difference $(\sim 0.05 \%)$ between the $\delta^{88 / 86} \mathrm{Sr}$ of modern day and Late Quaternary barites [2].

Marine barite forms in the water column and faithfully records the ${ }^{87} \mathrm{Sr} /{ }^{86} \mathrm{Sr}$ of seawater [3]. Recently, Paytan et al. showed that marine barite also records $\delta^{88 / 86} \mathrm{Sr}$ with a constant offset from the seawater composition [2]. Marine barite has several key advantages as an archive of seawater $\mathrm{Sr}$ composition. Barite is extremely insoluble and therefore resistant to dissolution or alteration in sediments. Further, the isotopic composition of marine barite is not subject to biological fractionation or temperature dependence during formation.

[1] Krabbenhöft et al. (2010), Geochimica et Cosmochimica Acta 74, 4097-4109. [2] Paytan et al. (submitted). [3] Paytan et al. (1993), Nature 366, 445-449. 